\title{
A DECADÊNCIA DO CARNAVAL NA ÓPTICA DA IMPRENSA PORTO-ALEGRENSE EM FINS DO SÉCULO XIX E INÍCIO DO XX
}

\author{
Caroline Pereira Leal*
}

Resumo: Ao findar o século XIX e no raiar do vindouro percebe-se na imprensa porto-alegrense um grande descontentamento com o tipo de festa carnavalesca que estava sendo feita na cidade. Este artigo procura demonstrar o formato que os festejos adquiriram nessa transição de século, bem como apontar para as razões que levaram a esse sentimento de insatisfação com o carnaval de Porto Alegre.

Palavras-chave: festas populares; carnaval; imprensa; saneamento moral; Porto Alegre.

The decline of Porto Alegre's carnival in the press view in the late nineteenth and early twentieth centuries

Abstract: At the end of the nineteenth century, one notices in the press Porto Alegre widespread discontent with the kind of carnival party that was being made in the city. This article seeks to demonstrate the format that the celebrations acquired end of this century, as well as point to the reasons that led to this feeling of dissatisfaction with the carnival of Porto Alegre.

Keywords: festivals, carnival; press; moral sanitation; Porto Alegre.

El declive del carnaval de Porto Alegre en la óptica de la prensa a finales de los siglos XIX y principios del XX

Resumen: A finales del siglo XIX se percibe en Porto Alegre una gran insatisfacción con el tipo de fiesta de carnaval que se están realizando en la ciudad. En este artículo se muestra el formato que las fiestas han adquirido en este siglo de transición y se busca señalar las razones que llevaron a esa sensación de insatisfacción con el carnaval de Porto Alegre.

Palabras clave: festivales; carnaval; prensa; saneamiento moral; Puerto Alegre.

* Doutora em História/PUCRS, Professora SMED/POA.

Recebido em: 30/09/2013 - Aceito em: 21/07/2014 
Ao analisarmos o carnaval em Porto Alegre percebemos que, ao findar o século XIX, a imprensa da cidade apresentava um discurso de desagrado com as manifestações que estavam ocorrendo por aqueles tempos. Esse artigo, portanto, busca apresentar o formato de festa carnavalesca deste período, representado pelos bailes públicos, pelo entrudo e confete e pelas festas realizadas por sociedades carnavalescas de cunho popular. Iremos explicitar esse descontentamento expresso pelos jornais em função dessas manifestações, apontando para três argumentos utilizados a fim de corroborarem suas críticas, tais como a imoralidade, a licenciosidade e a promiscuidade social. Desta forma, estamos discutimos não somente a prática carnavalesca em si, como também características que permearam a vida social porto-alegrense nessa virada de século, seus ideais vigentes que eram pautados pela noção de distanciamento e seleção social.

Grande parte do descontentamento expresso por alguns periódicos era em função do desaparecimento de duas tradicionais sociedades carnavalescas: Esmeralda e Venezianos. Para que entendamos melhor, vamos regressar um pouco no tempo.

$\mathrm{O}$ ano de 1873 foi um marco no carnaval porto-alegrense, surgiam as sociedades carnavalescas Esmeralda e Venezianos. Essas agremiações se propuseram a transformar os festejos na cidade, através de desfiles de carros alegóricos e bailes fechados para seus sócios. Queriam uma festa mais sofisticada, aos moldes de Nice e Veneza. Foram muitas vezes associados ao ideário moderno e de civilização.

Contudo, ao findar o século XIX, tais sociedades carnavalescas haviam desaparecido e o carnaval havia tomado outras formas. $\mathrm{O}$ luxo dos desfiles desaparecera. A sofisticação dos grandes bailes ficara na memória. Contudo, a população não deixara de celebrar essa data, só que agora não mais através da dita sofisticação do carnaval veneziano e sim ao seu modo e isso passou a incomodar muitos cronistas dos jornais porto-alegrenses, eram tidas como "tristes manifestações carnavalescas" (O Independente, Porto Alegre, 09 de março de 1905). 
Mas de que forma a população continuou comemorando esses três dias de festa? O que eram as "tristes manifestações carnavalescas"? Apresentaremos três modalidades de festejo executados àquela época: a. bailes de máscaras; b. entrudo e confetes e c. outras sociedades carnavalescas.

\section{Bailes de máscaras}

Entre as formas de comemoração do carnaval que eram criticados pela imprensa porto-alegrense encontramos os bailes de máscaras. Tais eventos eram noticiados de uma forma negativa, eram os "decantados bailes masqués" uma das "tristes manifestações carnavalescas" que se vira no ano de 1905. Sabemos que a apresentação das notícias, mais do que informação do registro ocorrido, denota as atitudes próprias de cada veículo de informação (ZICMAN, 1985:90). Desta forma, o periódico O Independente ${ }^{1}$, ao se referir a esse festejo, chamava a atenção para esses bailes a fim de que se zelassem pela moral pública da cidade.

Sem querer entrar na análise detalhada de todas as tristes manifestações carnavalescas dos três dias que vêm de passar, limitar-nos-emos a rápidas considerações sobre os decantados bailes masqués, chamando para eles a atenção de quem tem a obrigação de zelar pela moral pública. O Independente, Porto Alegre, 09 de março de 1905).

O jornal considerava aquele ano de 1905 como não tendo nenhum tipo de festa carnavalesca digna e demonstrava uma preocupação com a moral durante os bailes de máscaras. Sabemos

${ }^{1} \mathrm{O}$ periódico $O$ Independente foi uma folha de caráter informativo criada por Octaviano de Oliveira algum tempo após o fechamento d'A Gazetinha e que circulou até 1923 (STEYER, 2010:54). Segundo Vargas, “n'O Independente escreveram militantes socialistas, políticos e funcionários públicos de segundo e terceiro escalão, coronéis da Brigada Militar... homens cujos nomes e histórias não sobreviveram à passagem do tempo, apesar do eventual destaque em suas épocas"( VARGAS, 2007:2).

Idéias - Rev. Inst. Filos. Ciênc. Hum. UNICAMP, v.6, n.2, p.283-300, jul/dez. 2015 
que o anonimato que ela permite, facilitava a licenciosidade durante o festejo. A máscara, sendo uma

metáfora do anonimato, impede o olhar social que reconhece e amarra cada um ao seu próprio lugar, à sua própria identidade e ao que dela se espera. A suspensão do olhar social/censura, prática analítica e confessional, autoriza a fala do indizível. Faz surgir uma outra palavra, uma outra ação e, por que não dizer, os outros habitantes de nossa subjetividade" (LANZARIN, 2000:3).

É importante ressaltar que no ano seguinte, 1906, Esmeralda e Venezianos iriam ressurgir e que elas também fariam bailes com mascarados. Entretanto, não haverá este tom de reprimenda que existira anos atrás.

Em 1914, o jornal A Federação noticiava o controle que haveria no baile burlesco que a Esmeralda daria no Palacete Avenida, sendo que na "entrada do clube uma comissão encarregada do reconhecimento dos fantasiados, evitará com a conveniente descrição, que seja iludido o característico empenho seletivo da Esmeralda, quanto às suas festas de salão" (A Federação, Porto Alegre, 16 de fevereiro de 1914). Não havia, portanto, o tom moralizante e acusador de anos atrás, a despeito de serem bailes mascarados ou bailes masqués. Tal diferença pode ser explicada pela mudança nos atores que promovem a festa. O baile de agora é feito pela Esmeralda, a reunião dos seletos cidadãos porto-alegrenses. Além disso, note-se a preocupação com o reconhecimento dos

\footnotetext{
${ }^{2} \mathrm{O}$ jornal A Federação foi "fundado por Júlio de Castilhos para ser o baluarte de vitória e de manutenção do poder do Partido Republicano Rio-grandense, é de $1^{\circ}$ de janeiro de 1884, depois de cuidadosamente planejado, já que experiências anteriores haviam fracassado. Durará até 1937, quando é extinto por ato censorial, ainda que já se encontrasse em decadência desde após a Revolução de 1930. (HOHLFELDT,2006:2) A imprensa republicana já tivera antecedentes, no Rio Grande do Sul, com os jornais A democracia (1872-1874 ou 1875), A reação (1878), A imprensa (1880-1882) e A convenção (1883-1884) (RÜDIGER, 1984:13).
} 
mascarados, a fim de que se garantisse a seleção esmeraldina e ninguém se escondesse sob a máscara.

\section{Entrudo e Confetes}

Assim como os bailes de máscaras, as brincadeiras de entrudo $^{3}$, agora aliadas aos confetes, também passaram a ser "a marca de um triste carnaval" ' $O$ Independente, Porto Alegre, 09 de março de 1905). Na virada do século XIX para o XX, esse jogo parece ter sido o único registro dos dias carnavalescos. Segundo o jornal Correio do Povo ${ }^{4}$, o carnaval naquele ano:

quase que se circunscreveu ao jogo mais ou menos lícito do entrudo, mas, em todo o caso, bastante ofensivo dos bons costumes. Via-se em plena rua dos Andradas cada coisa...! quero dizer: cada bisnaga, que por si só era uma indecência.

${ }^{3}$ Brincadeira de origem ibérica,chegou ao Brasil com nossos colonizadores. Consistia no arremesso de limões de cheiro (esferas de cera com líquidos dentro), águas de baldes ou bacias, farinhas, tudo que pudesse sujar e molhar o adversário (LEAL, 2008:29). Nestes dias, "homens e mulheres se empenhavam em loucas correrias e agarramentos, jogando água. Era um salve-se quem puder!"(FLORES, 1999:149). De acordo com Cunha, além da molhadeira o entrudo compreendia uma série de troças de mascarados, bem como a pregação de peça em conhecidos ou passantes: "dias de molhadeiras, mas também dias de mentira e das pilherias que podiam, por vezes dar margem a incidentes desagradáveis se realizados fora de seu contexto específico" (CUNHA,2001: 25).

${ }^{4}$ De acordo com Rüdiger, o jornal Correio do Povo veio a público no ano de 1895, com a pretensão de ser um "periódico apartidário, não comprometido com a política, mas somente com a causa pública", diferindo-se dos demais jornais, nos quais "os partidos encarregaram-se de montar suas próprias empresas e lançar periódicos pelos quais assumiam inteira responsabilidade" (RÜDIGER, 1993:90).

Idéias - Rev. Inst. Filos. Ciênc. Hum. UNICAMP, v.6, n.2, p.283-300, jul/dez. 2015 
E, depois, o modo, o jeitinho, o descaro, a petulância com que o jogo era feito, não já entre parceiros, mas, o que mais é, entre tout le monde...(Correio do Povo, Porto Alegre, 04 de março de 1900).

O último carnaval do século XIX teria se restringido, segundo o cronista, somente ao entrudo. Esse fora chamado de "jogo mais ou menos lícito", denotando que - apesar de proibido e ilícito desde o ano de 1847(Livro de Registros de Posturas Municipais de 1829 a 1888.4 dez 1829, Porto Alegre, 1847) e os editais de sua proibição serem sempre publicados nos jornais a fim de relembrar aos foliões essa interdição - a permeância de sua prática chegara a torná-lo aceitável, apesar de sempre criticado. O jornal Correio do Povo sustentava sua critica ao entrudo acusando-o de ser "bastante ofensivo dos bons costumes" e não ser mais praticado entre parceiros, mas sim "entre tout le monde".

As imagens também foram veículos utilizados pela imprensa para que se corroborassem essas condenações ao entrudo ${ }^{5}$. Encontramos uma charge publicada no jornal $A$ Gazetinha ${ }^{6}$, na

\footnotetext{
${ }^{5}$ Segundo Zicmam, a imprensa como um todo constitui uma realidade específica com formas próprias, tendo ela uma linguagem característica. Esta é composta de três elementos principais: "a expressão escrita (textos, manchetes,...), a expressão icônica (fotos, desenhos,...) e a composição do jornal (distribuição dos artigos e colunas pelas páginas do jornal). ( ZICMAN, 1985:90).

${ }^{6}$ Segundo Steyer, A Gazetinha foi fundada em 1891 e tinha como proprietário Octaviano Manuel de Oliveira que era um homem de "instrução limitada, primária incompleta, pouco [excedendo] o nível do analfabetismo", não sendo, portanto, "um jornalista no exato sentido do vocábulo". De acordo com Vivaldo Coaracy, citado por Steyer, "a Gazetinha foi jornal de escândalo, explorando a fascinação que sobre os espíritos primários exerce o sensacionalismo grosseiro. Destacava-se pela violência da linguagem nos ataques pessoais em que nem mesmo a honra das famílias das pessoas visadas era poupada". Em agosto de 1899, Octaviano de Oliveira, ao voltar do teatro, sofreu um atentado de seus inimigos, o que o obrigou a fechar o jornal (STEYER, 2010:2-3).
} 
qual a representação da brincadeira aponta para o incômodo com conservação do antigo costume carnavalesco. Vejamos:

\section{FIGURA 1 - Charge sobre Entrudo}

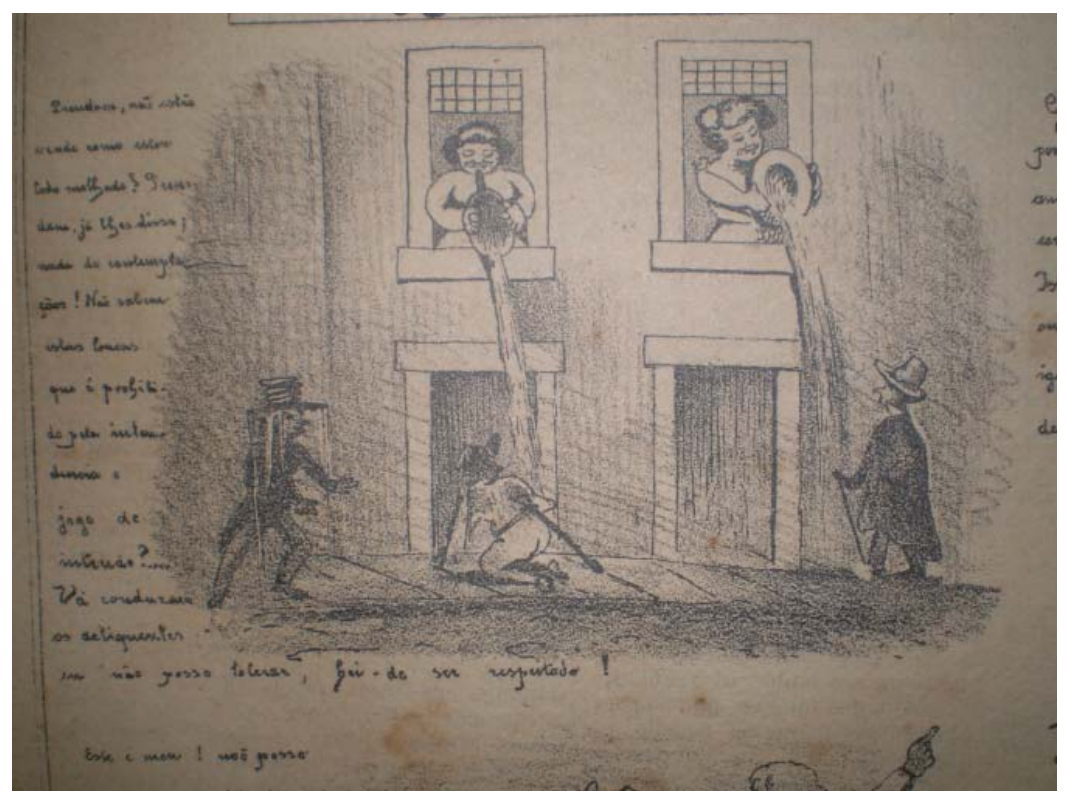

Fonte: Jornal A Gazetinha de 15 de fevereiro de 1896.

Na imagem visualizamos duas mulheres, cada uma em sua janela, atirando água de suas bacias nos homens que passavam pelas calçadas. Na legenda está escrito: “Prendam, não estão vendo como estou todo molhado? Prendam, já lhes disse; nada de contemplações! Não sabem estas loucas que é proibido pela intendência o jogo de entrudo? Vá conduzir as delinqüentes, eu não posso tolerar, hei de ser respeitado! Este é meu! Não posso". Através da legenda averiguamos um tom de reprimenda à permanência da brincadeira e a postura policial de apenas contemplar a sua existência, sem fazer com que se cumprissem as leis de proibição 
do jogo. É o “jogo mais ou menos lícito do entrudo"(Correio do Povo, Porto Alegre, 04 de março de 1900), de que falava a nota do Correio do Povo que mostramos acima. A brincadeira é executada por mulheres que de suas janelas banhavam aos homens que passavam sob elas. Estes, portanto, é que se apresentavam incomodados com a atitude feminina, ordenando para que elas fossem presas por tal ato.

O entrudo era um jogo que há tempos vinha sendo criticado. Como apontamos acima, era proibido desde 1847 e os jornais já haviam feito várias campanhas para que se abolisse essa prática. O próprio nascimento das sociedades carnavalescas se dá em sua função, um de seus objetivos era extirpar essa brincadeira dos hábitos carnavalescos porto-alegrenses.

Assim, nesta virada de século, ainda encontramos o entrudo sendo criticado pelos jornais da cidade. Os perigos e incômodos por ele proporcionados, bem como a ameaça aos bons costumes que ele oferecia eram evidenciados com desagrado. Brincadeira tida como perigosa e imoral, em virtude dos "abraços traiçoeiros que começam na porta da rua e iam terminar mesmo nas barbas dos senhores pais de família (A Reforma, Porto Alegre, 14 de fevereiro de 1875), havia ganhado um companheiro para as festas: o confete. Todavia, a brincadeira do confete era considerada menos imoral do que a do entrudo. O jornal Correio do Povo afirmava que não havia amor como o Amor molhado:

É pouco, é muito pouco para eles o inocente prazer de enroscar fitas de papel ou de peneirar confete sobre os bustos de suas amadas. E bem melhor lhes houvera de saber ao paladar o gostinho picante de escorropichar o líquido das suas bisnagas sobre formas que em pouco se lhes desenhariam patentes e precisas num vivo relevo, acentuado pela aderência de vestes úmidas que acompanhassem as linhas de todo o perfil.

$\mathrm{E}$ as corridinhas das tímidas? $\mathrm{E}$ as perseguições dos afoitos? E os encontrões involuntários? E os abalroamentos suaves? E todas essas mil peripécias de tão singulares escaramuças? (...) 
E por isso ponderava ontem um poeta lírico de muito sentimentalismo e muito nervo:

- Qual! No carnaval, como na opereta, não há como o Amor molhado! (Correio do Povo, Porto Alegre 07 de fevereiro de 1897).

A oportunidade de brincadeiras mais maliciosas, como a atitude fálica de atirar os líquidos das bisnagas sobre o colo das mulheres e deixá-las molhadas por ele, pareciam mais atrativas que as brincadeiras com confetes, na qual só o peneirava sobre o busto das amadas, de acordo com o jornal. No jogo do entrudo, a licenciosidade dava ares de ser mais exercitada e era ressaltada pelo jornal, como se fosse um atrativo a mais para a sua prática.

Mas se para uns o jogo do confete não representava maiores prazeres, nem maiores perigos, para outros ele também era motivo para muitas outras burlas. Em tom jocoso, um colunista do jornal A Gazetinha afirmava que "andam dizendo por aí":

que um conhecido negociante, quando está no auge do seu confete, atira-se junto com os mesmo, parecendo querer devorar inimiga... Cuidado não vá machucar a cartola...

Que tem causado grande sucesso o brinquedo do confete: uma jovem tomou tanto confete que, ao chegar em casa, foi desconhecida tal era a transformação que se via pelo rosto da moça... $\mathrm{E}$ a velha que ignorava $\mathrm{o}$ motivo de tantas cores, perguntou: Mariquinhas, que manchas são essas? Ao que ela respondeu: são confete de um moço da rua da praia mamãe.

Que uma respeitável casada, quando passava pela Rua dos Andradas foi agredida por uns moços, que lhe jogaram serpentina, e ela, furiosa pela falta de respeito, disse: tire essa tripa daqui, seu Chico, que eu quando quiser divertir-me tenho o meu marido em casa! Bravos como está comportada... 
Que uma costureira ao sair das oficinas, foi jogar confete com um caixeiro, no União...

Com certeza também viu lá as serpentinas...

Que uma senhora casada, na Rua da Praia, possuiuse tanto, no jogo do confete, que só gritava: sossega Leitão...

Essas familiaridades sem o conhecimento do marido, é mais do que ... grave...

Que o Martins da Luzo teve muita inveja do Marquez das castanholas, na noite de quinta-feira, por vê-lo todo atirado, no meio das moças, envolto nos confete.

Beija-Flor (A Gazetinha, Porto Alegre, 15 de fevereiro de 1896).

Assim como o entrudo, o confete também representava uma oportunidade de burla do controle paterno e de extravazamento da sexualidade, momento em que havia uma quebra do controle sobre o comportamento social. Conhecido negociante, mulher casada, jovem moça, costureira: vários são os tipos e as classes sociais apontadas pelo cronista que se deleitavam com a brincadeira do confete. E em todas as referências a conotação sexual e de burla dos condicionamentos morais são ressaltados: ora é a senhora casada que se divertia sem o conhecimento do marido, ora são os homens atirados no meio das moças.

Mas aquilo que para uns era atrativo, esta possibilidade de maior contato com o sexo oposto, para outros era o problema. $\mathrm{O}$ velho entrudo, acompanhado agora pelo confete, continuava, portanto, a ser o vilão da moral e dos bons costumes das famílias porto-alegrenses. 


\section{a - Outras sociedades carnavalescas}

Quando Esmeralda e Venezianos colocaram seus desfiles nas ruas e promoveram seus bailes lá em 1874, muitas outras sociedades também surgiram e adotaram esse estilo de carnaval: Congos, Floresta Aurora, Germânia ${ }^{7}$. Com o passar do tempo, cada vez mais foram surgindo outras sociedades carnavalescas que pretendiam render preito a Momo. E mesmo com a ausência de venezianos e esmeraldinos, estas sociedades continuariam a promoveram a sua festa, entre elas: Estrela D'Alva, XPTO, Vagalumes, Cara Duras, Roxa Saudade, Saca Rolhas, Netos do Diabo, para citar alguns nomes.

Essa popularização e democratização do carnaval de Porto Alegre foi, contudo, vista com maus olhos: seria este o seu problema. O jornal A Federação assinalava esta ideia, criticando as sociedades que se inspiraram em Esmeralda e Venezianos, mas que se pautavam mais por um escândalo moral.

Cumprindo a triste faina de 'não deixar morrer o carnaval', algumas 'sociedades' estacionavam junto aos coretos na rua dos Andradas e, ao som da música, entregavam-se ao 'maxixe desenfreado', em requebros exagerados e obscenos, com grande escândalo do burguês honesto que não leva a família ao teatro para não apreciar tais cenas a troco de dinheiro.(...) E ao dissiparem-se os sons do último Zé Pereira ${ }^{8}$ que

7 Germânia e Floresta Aurora não eram sociedades carnavalescas, mas durante o carnaval promoviam desfiles e bailes aos moldes de venezianos e esmeraldinos.

${ }^{8}$ Segundo Cunha, o zé-pereira era um desfile constante e popular do carnaval carioca já na segunda metade do século XIX. A troça teria, contudo, sofrido uma descaracterização no último quartel do século, passando a sofrer críticas em relação à perda de autenticidade. "Na frente do zé-pereira vem a bandeira, que consiste quase sempre em três ou quatro esteiras velhas pregadas a um bambu. [...] Atrás da bandeira desfilam os bumbos. Atrás dos bumbos vêm os tambores de latas de biscoito rufando à toda força". Tratava-

Idéias - Rev. Inst. Filos. Ciênc. Hum. UNICAMP, v.6, n.2, p.283-300, jul/dez. 2015 
recolhia-se, acudiram-nos à mente os dias gloriosos da Esmeralda e dos Venezianos, em que o Carnaval de Porto Alegre primava pelo luxo, pelo gosto, pelo espírito e pela excelência do pessoal que tomava parte nos festejos! (A Federação, Porto Alegre 28 de fevereiro de 1900).

A fim de não deixar morrer o carnaval, algumas sociedades - das quais nem os nomes são mencionadas pelo cronista apareceram naquele ano de 1900. No entanto, tais associações não eram representantes dos valores burgueses, o que fez o cronista recordar dos tempos de Esmeralda e Venezianos, essas sim verdadeiras emissárias de "luxo", "gosto" e "nobreza". Agora eram os representantes de outros segmentos que faziam a festa, à qual o "burguês honesto" não levaria a família. Além disso, essas novas sociedades apreciavam "maxixe desenfreadamente", dança criada por negros, que misturava elementos musicais africanos e europeus, conhecida na época como um ritmo mestiço (REIS, 1993). Essa dança sofreu fortes preconceitos por parte das elites brasileiras por ser considerada imoral. Segundo Monica Velloso, "ao reforçar a ordem corpórea e a expansão da gestualidade, o maxixe introduzia um processo de mudanças que punha em questão os referenciais dominantes do universo sensorial" (VELLOSO,2007:5). Observe-se que na nota do Correio do Povo é exaltada a forma como os corpos se mexem, "com requebros exagerados e obscenos" ( A Federação, Porto Alegre, 28 de fevereiro de 1900). Novamente, a preocupação com a licenciosidade e falta de moralidade no carnaval é evidenciada: seja no jogo de entrudo, nas brincadeiras com confetes ou nas danças proferidas por sociedades não representantes dos seletos grupos porto-alegrenses.

O carnaval que se seguiu ao fim das tradicionais sociedades não caiu, como já pudemos observar, no gosto da imprensa.

se de uma "presença coletiva", de grupos que atraíam muita gente atrás de si. Segundo a autora, "ele forneceu ritmo à dança [...] atraiu para a dança os diabinhos e demais personagens que, isolados, já pareciam assustadores" (CUNHA,2001:46). 
Três eram os argumentos mais utilizados para desqualificar as formas de brincar o folguedo: a imoralidade, a licenciosidade e a promiscuidade social. De acordo com Lazzari, os jornais faziam apelos à polícia pedindo "maior atenção na vigilância moral do carnaval" (LAZZARI, 1998:161), sendo que sua preocupação residia não só "na suposta imoralidade do entrudo, mas também na promiscuidade social, como se fossem dois perigos que andassem lado a lado"(Ibid.,1998:162) .

Anderson Vargas (VARGAS, 1992) em sua dissertação, teve como objeto de pesquisa o referido periódico $O$ Independente. Segundo o autor, "durante todo o período pesquisado, aquele periódico revelou uma verdadeira 'ânsia de civilização', um desejo irrestrito de progresso material e, ao mesmo tempo, um monocórdio lamento sobre a 'decadência' causada pelo desejado movimento de avanço"(VARGAS, 2007:02). Estes valores, percebidos por Vargas no referido jornal, estão presentes também nas falas a respeito dos festejos carnavalescos de Porto Alegre. Se, por um lado, a introdução do Carnaval, promovida por esmeraldinos e venezianos representava o progresso da cidade, através de uma civilizada comemoração; por outro, com o seu desaparecimento, o periódico alertava para uma

licenciosa libertinagem que vai aos poucos corrompendo a nossa juventude, em uma ameaça feroz e real às bases sacratíssimas do lar, à moral da família que é o fundamento do edifício social. Todas

\footnotetext{
${ }^{9}$ Alexandre Lazzari, em sua dissertação analisou o carnaval em Porto Alegre no período de 1870 a 1915, buscando entender de quem realmente era o carnaval nesse período: era ele do povo? O autor defendeu a hipótese de que havia, no carnaval porto-alegrense do final do século XIX, uma tradição baseada em adaptações, ressignificações e rejeições das novidades culturais da Corte carioca e da Europa, "conforme suas conveniências e condições sociais e políticas". Isso, posteriormente, teria facilitado a difusão dos símbolos de identidade nacional, pois já encontraria um "terreno preparado, de diferentes formas, nos maiores centros urbanos do território nacional, onde eles não eram estranhos às classes populares". (LAZZARI, 1998:12-13)
}

Idéias - Rev. Inst. Filos. Ciênc. Hum. UNICAMP, v.6, n.2, p.283-300, jul/dez. 2015 
essas considerações vem a propósito de festa pagã e lúbrica do carnaval (O Independente, Porto Alegre, 9 de março de 1905).

O Independente expressava, assim, sua preocupação com a moral social. A festa pagã e lasciva punha em risco as bases do lar e a moral das famílias ao perverter a juventude com sua devassidão. Era o carnaval a "celebração mais brutal e rude do culto da carne":

Vestígio cristão das saturnálias de decadência do império romano, em todos os tempos o carnaval foi a soberana festa da luxúria desenfreada, da devassidão mais profunda, celebração mais brutal e rude do culto da carne. (...) A moral de nossa sociedade periclita $(O$ Independente, Porto Alegre, 9 de março de 1905).

Identificado com a decadência do império romano, fazendo uma correlação com o declínio da cidade por aqueles tempos, o carnaval punha em risco a moral da sociedade portoalegrense, através da "luxúria desenfreada" e da "devassidão mais profunda". Essa preocupação com a devassidão, com a falta de moral - identificada como o fundamento do edifício social - e com a depravação eram assuntos frequentes na Porto Alegre da virada do século.

Alguns periódicos empenharam-se em campanhas de cunho moralizante, sobretudo, contra os hábitos culturais dos populares. Cláudia Mauch averiguou a partir da análise de jornais do século XIX, como a Gazeta da Tarde e a Gazetinha, a frequência e o destaque conferido aos temas de desordem e imoralidade. Tais folhas estavam engajadas em ajudar a promover o "saneamento moral" da capital. A utilização de expressões como "saneamento moral" e "doença social" revela a preocupação por parte dos jornalistas com a "saúde" do corpo social e, segundo Mauch, o grande problema para esses jornais era o perigo de contágio que a "parte ruim" representava, podendo "infectar a parte sã da sociedade" (MAUCH, 1994:11). De acordo com Millen,"o indivíduo desviante era encarado a partir de uma perspectiva moral em que os hábitos 
torpes e promíscuos dos populares corrompiam os valores burgueses" (MILLEN, 2006:62). Nessa linha, o jornal O Independente lamentava que, "com o decorrer dos tempos, as festas de Momo se têm tornado cada vez mais plebeias, mais abjetas" (O Independente, Porto Alegre, 9 de março de 1905).

A percepção da festa carnavalesca daquele momento como abjeta por ser protagonizada pelas classes populares pode ser interpretada a partir da premissa de que "as disposições adquiridas na posição ocupada implicam um ajustamento a esta posição" (BOURDIEU, 2004:155), ou seja, no caso aqui estudado, os agentes que ocupavam posições dominantes se recusavam a participar de um festejo que não era percebido como sendo do seu agrado, portanto, mantinham uma posição crítica à festa, tida como plebeia. Assim, para Bourdieu, a incorporação das disposições sociais por intermédio do habitus leva as pessoas a se amoldarem - conscientemente ou não - à sua posição no espaço social, a "guardarem as distâncias" (BOURDIEU, 2004:155). As classes sociais que ocupam uma posição superior no diagrama dos diferentes tipos de capital tenderiam a "manter[...] sua posição, a não ter[...] intimidades", mesmo que, eventualmente, adotem estratégias de condescendência, "através das quais agentes que ocupam uma posição superior em uma das hierarquias do espaço objetivo negam simbolicamente a distância social, que nem por isso deixa de existir" (BOURDIEU, 2004:154).

As festas não eram mais promovidas por esmeraldinos e venezianos. Segundo o cronista, com o transcorrer dos anos, elas se tornaram comemorações mais rudes, mais simples. $\mathrm{O}$ reinado de Momo estava sendo feito por plebeus! Para o jornal, continuar com tais práticas carnavalescas seria contaminar toda a sociedade, quebrar a distância social desejada e, por conseguinte, se colocava contra a festa pagã. A mesma festa, se celebrada por Esmeralda e Venezianos, não era condenada, pois esta era a expressão da alegria da população. Sem elas, de acordo com Lazzari, era como se "não existisse um carnaval digno desse nome. Era em torno delas que, nesse momento, se construía uma imagem idealizada para a festa e uma memória positiva para os seus feitos do passado, 
em oposição direta com os valores 'degenerados' do carnaval das ruas" (LAZZARI,2001:18).

Havia, portanto, uma apreensão com uma possível degeneração moral, expressa nos festejos carnavalescos, aonde o perigo de contaminação e decomposição da sociedade jazia em manifestações carnavalescas populares como, por exemplo, as brincadeiras de rua e os bailes públicos, que passaram a ser considerados "um foco de contaminação, ameaçando a moral de toda a sociedade" (LAZZARI,2001:18). Essa apreensão poder ser verificada em diversos periódicos da capital, até mesmo entre os que não tinham uma explícita posição política defendida, como no caso do Correio do Povo. Se com a presença de Esmeralda e Venezianos a imprensa o identificava no carnaval ideais de modernidade, progresso e civilização, com o seu desaparecimento a mesma festa passou a representar a imoralidade, a decadência, ao expor a "parte ruim" da sociedade e colocar em risco a "parte sã".

O fato das manifestações carnavalescas serem populares, portanto, parece ter sido o motivo do desencanto e desse sentimento de decadência proferido pelos jornais em relação ao carnaval quando adentramos o século XX. A festa atual era promovida não por representantes dos valores burgueses e tinha se tornado cada vez mais plebeia, como salientou o cronista do jornal $\mathrm{O}$ Independente. E aí residia o perigo: para esses comentaristas, o festejo traduzia a tendência degenerada e mórbida à imoralidade de seus atores. Havia se popularizado e a difusão dos valores e sentidos pertencentes a outras classes sociais deflagrara um combate, levado a cabo por diversos veículos da imprensa de Porto Alegre, à imoralidade, à licenciosidade e à promiscuidade social que passara a ser vista como condenável no carnaval. 


\section{Bibliografia}

BOURDIEU, Pierre. Espaço Social e Poder Simbólico. In: Coisas Ditas. São Paulo: Brasiliense, 2004, p. 155.

CUNHA, Maria C. P. Ecos da Folia: uma história social do carnaval carioca entre 1880 e 1920. São Paulo: Companhia das Letras, 2001.

FLORES, Moacyr. Do entrudo ao carnaval. Estudos IberoAmericanos, XXII (1) - junho, 1999.

HOHLFELDT, A.; RAUSCH, F. A imprensa sul-rio-grandense entre 1870 e 1937: Discussão sobre critérios para uma periodização. NP de Jornalismo, do XXIX Congresso Brasileiro de Ciências da Comunicação, Universidade de Brasília, Distrito Federal, 2006.

LANZARIN, Claudia Cruz. A fantasia e o baile de máscaras do final do milênio. Psicol. cienc. prof., Brasília, v. 20, n. 3, set. 2000. Disponível em http://pepsic.bvsalud.org/scielo.php, acessado em 30 set. 2012.

LAZZARI, Alexandre. Certas coisas não são para que o povo as faça: Carnaval em Porto Alegre (1879-1915). Dissertação de Mestrado. IFCH/UNICAMP, Campinas, 1998.

MAUCH, Claudia et all. Porto Alegre na virada do século 19; cultura e sociedade. Porto Alegre: Ed. da Universidade, 1994, p. 11.

MILLEN, Carlos. Marginais e desviantes: criminalidade e controle social na Porto Alegre dos anos de 1890 e 1900. IV Mostra de pesquisa do Arquivo Público do Estado do Rio Grande do Sul. Anais: produzindo história a partir de fontes primárias. Porto Alegre: CORAG, 2006, 304 p, p. 62.

REIS, Letícia Vidor de Souza. Negros e brancos no jogo da capoeira: a invenção da tradição. Dissertação de mestrado. São Paulo, USP, 1993. 
RÜDIGER, Francisco Ricardo. A Federação e o processo políticoideológico rio-grandense (1884-1937). In: Comunicação $\mathcal{E}$ Cultura, Porto Alegre, Museu de Comunicação Social Hipólito José da Costa, 1984, nº 1, ps. 12 a 21.

RÜDIGER, Francisco. Tendências do Jornalismo. Porto Alegre: Ed.UFRGS, 1993.

STEYER, Fábio Augusto. Reflexões sobre a história do jornalismo no Rio Grande do Sul: uma experiência de pesquisa. Anais I Encontro de História da Mídia.UNICENTRO, Guarapuava/PR, 2010.

VARGAS, Anderson Zalewski. Os Subterrâneos de Porto Alegre. Imprensa, ideologia autoritária e reforma social (Porto Alegre 1900/1919). Dissertação de Mestrado, PPGH/UFRGS, Porto Alegre, 1992.

VARGAS, Anderson. Usos da Antiguidade: imprensa, civilização e decadentismo no sul Brasil Republicano. Liber Intellectus, v. 02,2007 , p. 02.

VELLOSO, Mônica Pimenta. A dança como alma da brasilidade. Nuevo Mundo Mundos Nuevos, n. 7, mis en ligne le 15 mars 2007, référence du 15 septembre 2007. Disponible sur: http://nuevomundo.revues.org/document3709.html.

ZICMAN, Renée Barata. História através da imprensa: algumas considerações metodológicas. Projeto História. Revista do Programa de Estudos Pós-Graduados de História. v. 4, 1985. 